\title{
Prospecção cientifica e tecnológica de produtos funcionais a base de patê de
}

\section{pescado}

\author{
Scientific and technological prospection of functional products based on fish pate \\ Prospección científica y tecnológica de productos funcionales a base de paté de pescado
}

Recebido: 18/01/2022 | Revisado: 22/01/2022 | Aceito: 27/01/2022 | Publicado: 29/01/2022

Bruna Vieira da Silva

ORCID: https://orcid.org/0000-0003-3743-4104 Universidade Federal do Recôncavo da Bahia, Brasil

E-mail: vieira_bruna@hotmail.com

Lucas Guimarães Cardoso

ORCID: https://orcid.org/0000-0002-6674-338X

Universidade Federal de São Carlos, Brasil

E-mail: lucaseng.pesca@yahoo.com.br

Mariza Alves Ferreira

ORCID: https://orcid.org/0000-0001-9238-9161 Universidade Federal do Recôncavo da Bahia, Brasil E-mail: marizaufrb@yahoo.com.br

Jéssica Ferreira Mafra

ORCID: https://orcid.org/0000-0001-8833-7158 Universidade Federal do Recôncavo da Bahia, Brasil E-mail: jelmafra@hotmail.com

Norma Suely Evangelista-Barreto

ORCID: https://orcid.org/0000-0001-5960-0957 Universidade Federal do Recôncavo da Bahia, Brasil E-mail: nsevangelista@ufrb.edu.br

\begin{abstract}
Resumo
O presente estudo teve como objetivo realizar um levantamento de informações tecnológicas e científicas relacionadas a produção de patê de peixe funcional. As buscas foram realizadas em documentos de patentes disponíveis no Banco de dados Espacenet, utilizando as palavras-chave pâté AND fish AND A23L17/00. O maior número de documentos depositados foi observado no ano de 2003, sendo a Rússia a maior depositante com 29,3\% de documentos. Desse total os inventores independentes foram requerentes em $47 \%$ dos depósitos. Entre os documentos analisados, 39,65\% tratam do processo de produção do produto, $34,48 \%$ de tecnologias e $25,86 \%$ de produtos. Dentre os artigos revisados, $60 \%$ dos patês foram bem aceitos entre os provadores, com índice de aceitação superior a $70 \%$. O estudo de prospecção cientifica e tecnológica agrega contribuições importantes para a ciência, principalmente, para o desenvolvimento de novos produtos na área de alimentos. Dessa forma, a partir dos documentos de patentes selecionados foi possível constatar a ausência de detentores de patentes no Brasil acerca do tema analisado demonstrando que o país necessita de maiores investimentos na pesquisa científica, apesar de serem observados a publicação de artigos científicos sobre o tema, podendo este ser uma oportunidade para o desenvolvimento de inovação para o setor de alimentos provenientes do pescado.
\end{abstract}

Palavras-chave: Patentes; Pescado; Inovação tecnológica.

\begin{abstract}
The present study aims to conduct a survey of technological and scientific information related to the production of functional fish pâté. The searches were carried out in patent documents available in the Espacenet database, using the keywords pâté $A N D$ fish $A N D A 23 L 17 / 00$, with the analysis of the data performed in Excel spreadsheets. The largest number of documents deposited was observed in 2003, with Russia being the largest depositor with $29.3 \%$ of documents. Of this total, independent inventors were applicants in $47 \%$ of the deposits. Among the documents analyzed, $39.65 \%$ deal with the product production process, $34.48 \%$ of technologies and $25.86 \%$ of products. Among the reviewed articles, $60 \%$ of the pates were well accepted among the tasters, with an acceptance rate higher than $70 \%$. The study of scientific and technological prospecting adds important contributions to science, especially for the development of new products in the food area. Thus, from the selected patent documents it was possible to verify the absence of patent holders in Brazil on the analyzed theme demonstrating that the country needs greater investments in scientific research, despite the fact that the publication of scientific articles on the subject is observed, and this may be an opportunity for the development of innovation for the fish food sector.
\end{abstract}

Keywords: Patents; Fish; Technological innovation. 


\section{Resumen}

El presente estudio tiene como objetivo realizar un estudio de la información tecnológica y científica relacionada con la producción de paté de pescado funcional. Las búsquedas se realizaron en documentos de patentes disponibles en la base de datos Espacenet, utilizando las palabras clave paté Y pescado Y A23L17/00, con el análisis de los datos realizado en hojas de cálculo Excel. El mayor número de documentos depositados se observó en 2003, siendo Rusia el mayor depositante con el 29,3\% de los documentos, siendo los inventores independientes los mayores solicitantes con el $47 \%$ de los depósitos. Entre los documentos analizados, el 39,65\% se ocupa del proceso de producción del producto, el 34,48\% de las tecnologías y el 25,86\% de los productos. Entre los artículos revisados, el $60 \%$ de los patés fueron bien aceptados entre los catadores, con una tasa de aceptación superior al $70 \%$. El estudio de la prospección científica y tecnológica aporta importantes aportes a la ciencia, especialmente para el desarrollo de nuevos productos en el área alimentaria. Así, a partir de los documentos de patente seleccionados se pudo verificar la ausencia de titulares de patentes en Brasil sobre el tema analizado demostrando que el país necesita mayores inversiones en investigación científica, a pesar de que se observa la publicación de artículos científicos sobre el tema, y esto puede ser una oportunidad para el desarrollo de innovación para el sector de alimentos para peces.

Palabras clave: Patentes; Pescado; Innovación tecnológica.

\section{Introdução}

Estudos de prospecção tecnológica apresentam potencial importância para os sistemas de inovação, assegurando direitos legais sobre produtos, subprodutos e processos, revelando uma perspectiva atual do nível de aprimoramento em que se encontra antes de iniciar o processo de desenvolvimento tecnológico (Araujo Neto et al., 2020). De acordo com um estudo realizado por Batterink et al. (2006), as empresas alimentícias que apostam no desenvolvimento da inovação para implantação no mercado são as que obtém maior sucesso na inovação. Dentre os motivos que levam a busca constante por produtos inovadores estão a redução de custos, aumento da qualidade dos produtos, diminuição dos impactos ambientais, oportunidade de novos negócios, aprimoramento da capacidade produtiva das empresas, além do alinhamento entre os provedores e receptores aptos ao consumo (Rambe \& Khaola, 2021).

A partir das mudanças alimentares e hábito de vida das pessoas, ao longo dos anos, houve uma redução da qualidade alimentar, provocando modificações no organismo e acarretando em um déficit nutricional, com isso, os consumidores estão em busca de alimentos mais saudáveis (Moraes et al., 2017). Para suprir essa necessidade há uma busca contínua, da indústria alimentícia, por novos produtos que agregam benefícios para a saúde. Nesse contexto, uma tendência recente que vem ocupando espaço no mercado, são os alimentos funcionais, cujo consumo pode proporcionar ao organismo fontes de flavonoides, fitoquímicos, polifenois e vitaminas essenciais (Granato et al., 2020; Lobine et al., 2021).

Devido as condições favoráveis do clima no Brasil, o país será, em 20 anos, o maior produtor mundial de pescado, superando, atualmente, a produção de 800 mil toneladas de pescado, dentre as quais $60 \%$ da produção é representada pela tilápia, além disso, até o ano de 2020 o consumo mundial de pescado per capita apresentou tendência crescente com 20,5 Kg/ano (FAO, 2020; PEIXE BR, 2021). Dessa forma, o aumento do consumo de pescado possibilita o uso e aproveitamento dos subprodutos para o enriquecimento nutricional de outros gêneros alimentícios (Jaziri et al., 2021).

Entre os produtos destacados nesse cenário, merecem destaque os elaborados à base de pescado como o patê de peixe, por apresentar versatilidade de consumo, uma vez que podem ser consumidos como a principal refeição ou como aperitivos (Flores, 2019; Zolotokopova et al., 2021). Uma das estratégias para a reformulação do patê de peixe tradicional como um alimento funcional, pode ser produzido a partir da adição da biomassa de banana verde (BBV) e quitosana. Além disso, a utilização da carne mecanicamente separada - CMS para a produção do patê de peixe auxilia na redução de resíduos de peixe que são descartados no ambiente, podendo ser utilizada para a produção ou reformulação de novos produtos (Bernadino Filho \& Xavier, 2019).

A biomassa de banana verde é um ingrediente do tipo prebiótico devido a presença do amido resistente em sua composição, apresentando baixos teores de lipídeos e açúcares. A sua adição contribui para o aumento do volume do produto, 
além de fornecer vitaminas, minerais e fibras podendo ser utilizado como ingrediente na formulação de alimentos terapêuticos (Das et al., 2022; Raniere \& Delani, 2014). Já a quitosana é um polímero natural extraído de crustáceos que pode ser utilizada em alimentos, por apresentar propriedades antimicrobianas e antioxidantes, além de sua biocompatibilidade e atoxicidade (Irastorza et al., 2021).

Embora sejam encontrados diversos tipos de patês sendo produzidos e comercializados, é necessário que produtos inovadores sejam propostos, apresentando características benéficas para a saúde, uma vez que os consumidores estão cada vez mais preocupados com a saúde e alimentação saudável. Este estudo prospectivo tem como objetivo realizar um levantamento de informações tecnológicas e científicas relacionadas a produção de patê de peixe funcional.

\section{Metodologia}

Inicialmente, foi elaborada uma tabela de escopo utilizando palavras-chave em inglês que representassem o objetivo do trabalho em combinação à Classificação Internacional de Patentes - CIP referente ao pescado, através da combinação dos termos pâté, fish, seafood, chitosan, "green banana biomass" em combinação aos códigos A23L17/00 e A23L33/00.

Após a elaboração da tabela de escopo, foram realizadas buscas por documentos de patentes utilizando as palavraschave pâté, fish e o código A23L17/00, seguido do conectivo AND entre as palavras-chave, formando a busca pâté AND fish AND A23L17/00. A combinação das palavras foi escolhida por fornecer uma quantidade de documentos de patentes (285) satisfatória para a realização do estudo. Para a seleção dos documentos foram considerados os títulos e abstracts, tendo como base de dados o Banco de dados Espacenet (EPO), por ser a plataforma de maior variedade e facilidade de acesso, com patentes depositadas em mais de 90 países, incluindo o Brasil.

Para a tabela de revisão de literatura foram realizadas buscas de artigos científicos no banco de dados Google Acadêmico. O levantamento bibliográfico foi realizado utilizando as palavras-chave: patê, alimento funcional, pescado.

A análise dos dados foi realizada após organização dos dados em planilhas de Excel 2013 versão 15.0.4420.1017.

\section{Resultados e Discussão}

A partir da busca de documentos de patentes utilizando as palavras-chave e CIP foi possível elaborar a tabela de escopo e definir a combinação que expressava o objetivo do estudo (Tabela 1). Após realização das buscas foi possível eleger a melhor combinação (pâté AND fish AND A23L17/00) com a obtenção de 285 documentos. Em 67\% dos documentos selecionados, os produtos eram denominados de "pasta", enquanto 33\% eram designados como "patê". Ambos, igualmente incluídos no estudo por se tratar de termos utilizados para a mesma definição conforme estabelecido no artigo de no. 343 do Regulamento da Inspeção Industrial e Sanitária de Produtos de Origem Animal - RIISPOA (Brasil, 2017), onde patê de pescado também pode ser definido como pasta de pescado, desde que siga as especificações do decreto, sendo um produto industrializado obtido a partir do pescado transformado em pasta, com adição de ingredientes, e submetido a processos tecnológicos específicos. 
Tabela 1. Número de patentes por palavras-chave e código de classificação.

\begin{tabular}{|c|c|c|c|c|c|c|c|}
\hline Pâté & Fish & Seafood & Chitosan & $\begin{array}{l}\text { "Green } \\
\text { banana } \\
\text { biomass" }\end{array}$ & A23L17/00 & A23L33/00 & $\mathrm{N}^{\mathrm{o}}$ de patentes \\
\hline & $\mathrm{X}$ & & & & & & 847.490 \\
\hline \multirow[t]{5}{*}{$\mathrm{X}$} & & & & & & & 253.362 \\
\hline & & & $X$ & & & & 200.050 \\
\hline & & $X$ & & & & & 62.080 \\
\hline & $X$ & $X$ & & & & & 30.663 \\
\hline & $\mathrm{X}$ & & $\mathrm{X}$ & & & & 22.333 \\
\hline \multirow[t]{3}{*}{$X$} & $X$ & & & & & & 4.194 \\
\hline & & & & $\mathrm{X}$ & & & 3.262 \\
\hline & & $\mathrm{X}$ & $\mathrm{X}$ & & & & 2.480 \\
\hline \multirow[t]{2}{*}{$\mathrm{X}$} & & & $\mathrm{X}$ & & & & 1.832 \\
\hline & $X$ & & & $X$ & & & 1.007 \\
\hline $\mathrm{X}$ & & $X$ & & & & & 394 \\
\hline \multirow[t]{2}{*}{$\mathrm{X}$} & $\mathrm{X}$ & & & & $\mathrm{X}$ & & 285 \\
\hline & & $X$ & & $X$ & & & 124 \\
\hline $\mathrm{X}$ & $X$ & & & & & $X$ & 77 \\
\hline $\mathrm{X}$ & & & & $\mathrm{X}$ & & & 57 \\
\hline
\end{tabular}

Fonte: Autoria própria (2021).

Dos 285 documentos encontrados, apenas 58 estavam relacionadas ao tema de interesse associado ao CIP A23L17/00, e, portanto, utilizadas para o estudo prospectivo. De acordo com a Figura 1 observa-se a evolução anual de depósitos de patentes.

Figura 1. Evolução anual de patentes depositadas.

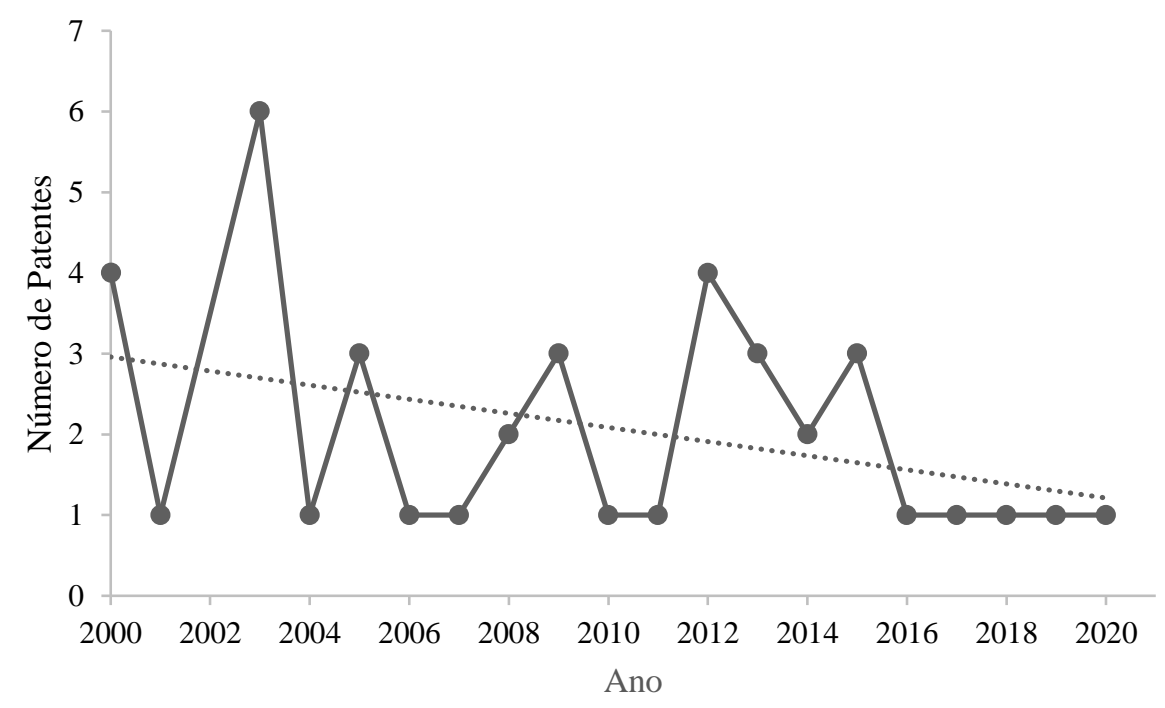

Fonte: Autoria própria (2021).

A primeira patente depositada nos últimos 20 anos (2001), trata do método de obtenção de produtos à base de peixe e vegetais na forma de pasta ou patê de modo a conter características de alimento funcional devido a presença de ácidos graxos poli-insaturados ômega-3, em especial o ácido eicosapentaenóico (EPA) e o ácido docosahexaenóico (DHA). De acordo com os detentores da patente, o principal objetivo dos métodos de produção é a elaboração de produtos com ótimas características organolépticas a partir de produtos com baixa adequação tecnológica (Kolodziejski et al., 2001). 
O maior número de documentos foi observado no ano de 2003 (Figura 1) e inclui patentes que tratam de tecnologias que abordam novas técnicas de esterilização e pasteurização do patê de peixe, bem como apresenta a descrição do produto ou processo de produção de pastas de peixe com características funcionais, com destaque para a fermentação de nutracêuticos, cereais, vegetais, frutas, turmarina e carvão vegetal, além de enzimas dietéticas e fitoterápicos (Mortier \& Mortier, 2003; Sokolova et al., 2003; Son, 2003a; Shirade, 2003; Son, 2003b; Son, 2003c).

Ao avaliarmos a linha de tendência (Figura 1) é observado uma queda expressiva no número de depósitos de patentes ao longo dos anos, com maior atenção para o período a partir do ano de 2016. Segundo Santos et al. (2018) uma das razões do baixo quantitativo de documentos de patentes encontrados nos últimos anos é atribuída aos 18 meses de sigilo das patentes após a data de depósito até a sua publicação, o que justifica a ausência de documentos de patentes no ano de 2021 e o baixo quantitativo no ano de 2020. Por outro lado, a redução do número de documentos de patentes depositadas entre os anos de 2016 à 2019 pode estar associado à crise global que se iniciou em 2008 e durou por uma década, uma vez que, o impacto negativo na entrega de tecnologias das instituições de pesquisa para as empresas é afetado devido ao déficit na economia, de modo que os investimentos em inovação são reduzidos (Micaelo \& Castro, 2021).

Ao analisarmos o número de documentos de patentes depositados por país (Figura 2), a Rússia foi o país com maior número de depósitos, representando 29,3\% do total de depósitos. O governo da Rússia aposta no desenvolvimento da inovação em todos os setores do país com principal atenção para a Ciência e Tecnologia, o que justifica sua liderança na produção de patês de peixes (Paranhos \& Sá, 2013). Além disso, de acordo com a FAO (2016) a Rússia está entre os maiores produtores de pescado do mundo com exportações para diversos países.

Em segundo lugar se encontram a Organização Mundial de Propriedade Intelectual ou World Intellectual Property Organization - WO (25,86\%) e a Organização Europeia de Patentes ou European Patent Office - EP (17,24\%). Tanto a WO quanto a EP são organizações que englobam vários países membros, sendo 180 países signatários para a WO, incluindo o Brasil, e 38 países da Europa, para a EP, incluindo todos os Estados-Membros da União Europeia. Países como o Canadá, França e Japão apresentaram o mesmo percentual de depósitos (3,44\%), da mesma forma que os Estados Unidos, China, Espanha, Reino Unido, Letônia e Polônia foram depositantes de 1,72\% das patentes e a República da Coréia depositante de 6,89\% das patentes.

Figura 2. Número de patentes depositadas por país.

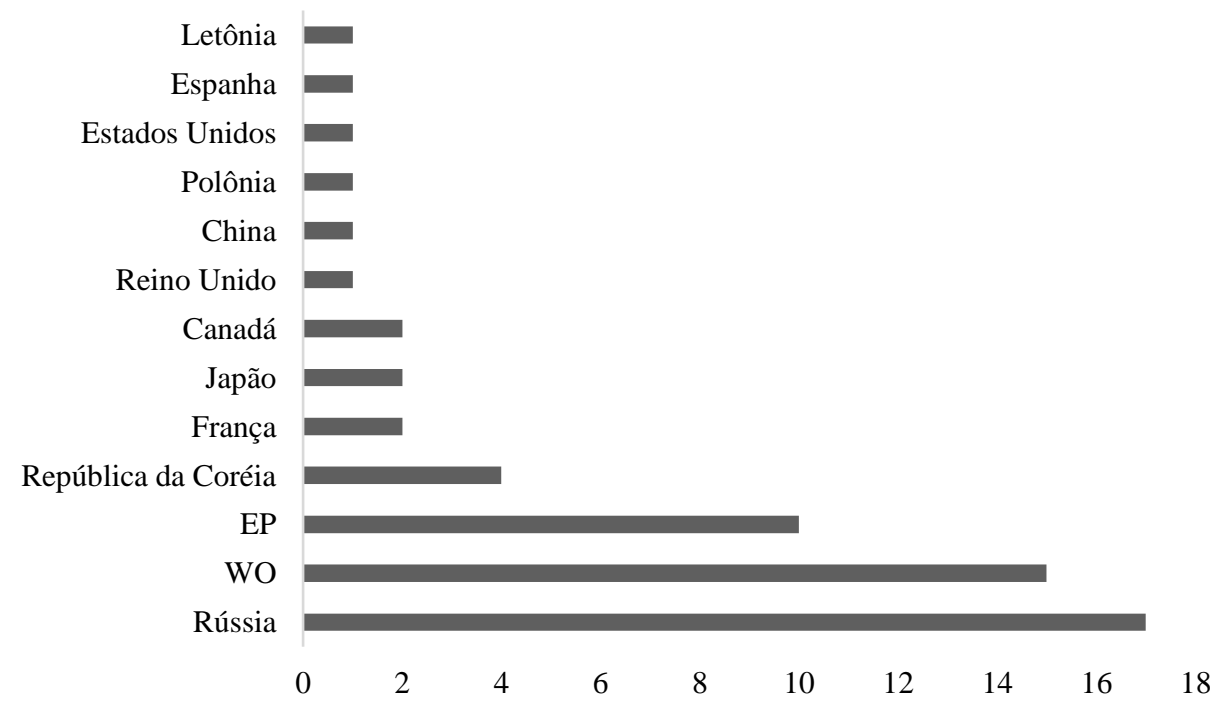

*EP: European Patent Office; **WO: World Intellectual Property Organization. Fonte: Autoria própria (2021) 
O Brasil não aparece como detentor de patentes da tecnologia analisada, embora Moura et al. (2019) relatam que os pedidos de patentes têm sido ampliados no Brasil, devido a criação de leis que promovem o seu incentivo, como a Lei de Inovação, principalmente no âmbito universitário. Por outro lado, o consumo médio de peixes pelos brasileiros ainda é baixo, se encontrando abaixo do recomendado que é de $12 \mathrm{~kg} / \mathrm{ano}$ (FAO, 2018). Um estudo realizado por Maciel et al. (2015) demonstrou que 24,8\% dos entrevistados na pesquisa consumiam pescado de duas a três vezes por mês, enquanto 1,9\% nunca consumiam, em virtude do elevado valor e sabor, associado a falta de hábito de consumo; já dentre os atributos destacados como relevantes para a compra, atribuíram o sabor para 59,0\% dos entrevistados, o tamanho (45,7\%), a embalagem (44,6\%) e o preço (48,6\%).

Segundo os índices gerais apresentados pela Organização Mundial de Propriedade Intelectual - OMPI (2018), a Rússia aparece entre os 10 primeiros Institutos com os maiores números de pedidos de patentes, apesar de nos últimos anos ter ocorrido uma diminuição $(-11,3 \%)$ dos pedidos de depósitos. Entre os cinco principais Institutos pode-se destacar EP e a República da Coréia, o primeiro apresentando um número crescente de pedidos de patentes, enquanto a República da Coréia apresenta um declínio nos pedidos e se encontra entre os cinco países que possuem os maiores números de pedidos de depósito (67.484) em outros países.

Além do código A23L17/00 utilizado nas buscas, outras classificações importantes também foram atribuídas aos documentos avaliados, sendo encontrados 8 códigos de classificação distintos (Figura 3), todos pertencentes a seção A que correspondia a "necessidades humanas" e a classe 23 que tratava de "alimentos ou gêneros alimentícios; tratamento dos mesmos, não cobertos por outras classes", representando o principal código de classificação encontrado (Tabela 2).

Figura 3. Número de patentes por Código de Classificação Internacional.

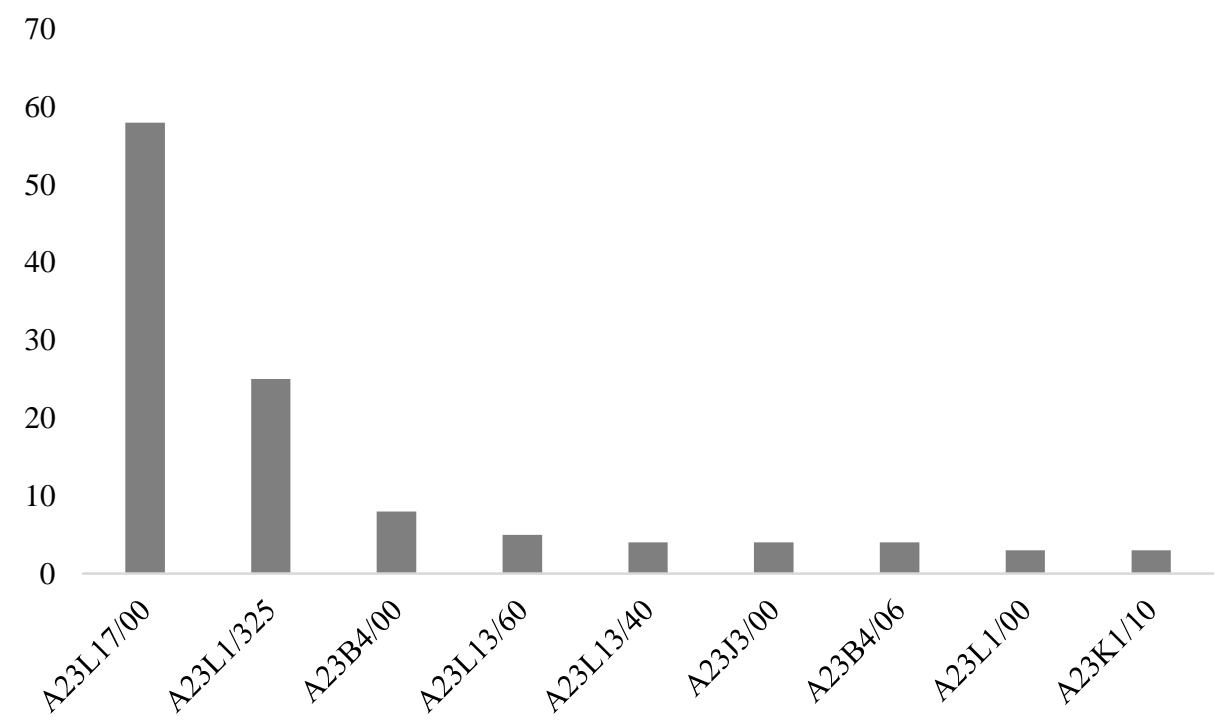

Fonte: Autoria própria (2021). 
Research, Society and Development, v. 11, n. 2, e40211225886, 2022

(CC BY 4.0) | ISSN 2525-3409 | DOI: http://dx.doi.org/10.33448/rsd-v11i2.25886

Tabela 2. Classificação dos códigos encontrados na pesquisa (pâté and fish and A23L17/00).

\begin{tabular}{|c|c|}
\hline Código & Classificação \\
\hline A23L17/00 & $\begin{array}{l}\text { Produtos alimentares do mar; Produtos de pesca; Farinha de peixe; Sucedâneos de ovo de peixe; } \\
\text { Preparação ou tratamento. }\end{array}$ \\
\hline A23L1/325 & Produtos alimentares provenientes da pesca marítima. \\
\hline A23B $4 / 00$ & Métodos gerais para conservar carne, salsichas, peixes ou produtos de peixe. \\
\hline A23L13/60 & $\begin{array}{l}\text { Produtos de carne triturado ou emulsionados, por exemplo, salsichas; carne reformada de produto } \\
\text { de carne triturada. }\end{array}$ \\
\hline A23L13/40 & ... contendo aditivos. \\
\hline $\mathrm{A} 23 \mathrm{~J} 3 / 00$ & Processamento de proteínas para alimentos. \\
\hline A23B $4 / 06$ & Congelamento; Descongelamento subsequente; Resfriamento. \\
\hline A23L $1 / 00$ & Alimentos ou gêneros alimentícios; Sua preparação ou tratamento. \\
\hline A $23 \mathrm{~K} 1 / 10$ & ... de carne, peixe ou ossos; do lixo da cozinha. \\
\hline
\end{tabular}

Fonte: Autoria própria (2021).

A Figura 4 representa a porcentagem de patentes conforme seus depositantes. Os inventores independentes apresentaram o maior número de patentes depositadas, com cerca de 47\%. As Empresas depositaram 38\% das patentes, enquanto as Instituições de Pesquisa 15\%, distribuídas entre 13 Instituições distintas, sendo 10 depósitos pertencentes a Rússia, 2 para a Organização Mundial de Propriedade Intelectual e 1 para a Polônia. Apesar do baixo quantitativo de documentos de patentes depositadas pelas Instituições de Pesquisa, percebe-se um esforço dos governantes para aumentar a produção e pedidos de depósitos de patentes nas Instituições (Mueller \& Perucchi, 2014). Dentre as empresas depositantes, merecem destaque a Ajinomoto e a Nippon Suisan Kaisha LTD, conhecida popularmente como Nissui, ambas empresas japonesas do ramo alimentício. A Ajinomoto possui produtos distribuídos em diversos países, incluindo o Brasil, já a Nissui é uma das maiores empresas de pesca e alimentos do país. Do total de inventores, 57,5\% possuem os depósitos de patentes vinculados a empresas, enquanto $10 \%$ estão vinculados a Instituições de Pesquisa, onde observa-se a presença de diversos pesquisadores com pedido de depósito individual ou vinculados a empresas.

Figura 4. Número de patentes por depositantes.

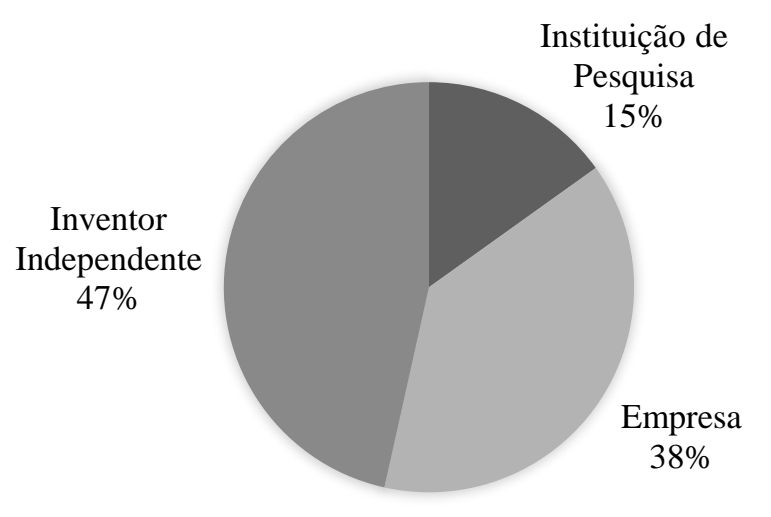

Fonte: Autoria própria (2021). 
$\mathrm{Na}$ análise individual dos documentos de patente observou-se que 39,65\% tratavam do processo de produção e/ou elaboração de produto; 34,48\% relatavam tecnologias correlatas, como a elaboração de patê de carne de peixe que, no estado final imita, por exemplo, o formato de uma vieira (molusco bivalve da família Pectinidae), e 25,86\% eram relacionadas ao produto final.

Em relação às espécies de peixes utilizadas no patê (Figura 5), a maioria (58\%) foi tratada apenas como "patê de peixe" sem especificação da espécie, seguido por Salmão (Salmo salar) (9\%), Polaca do Alasca (Gadus chalcogrammus) (7\%) e bacalhau (Gadus morhua) (6\%). A maior escolha do salmão para a elaboração de produtos pode estar associada a crescente produção aquícola nos países desenvolvidos, e maior frequência nos cardápios, por se tratar de uma espécie com grande aceitação no mercado mundial devido aos benefícios nutricionais como a presença dos ácidos graxos ômega-3 (Cyrino et al., 2019; PEIXE BR, 2021; Sozo et al., 2017). Assim como o salmão, o bacalhau também é direcionado para uma faixa da população que apresenta alto poder aquisitivo (Castro et al., 2019). Além disso, é considerado um alimento de elevada expressão gastronômica, estando presente na lista dos peixes mais consumidos da Europa (Gamito, 2019).

Figura 5. Tipos de peixes utilizados na elaboração de patês por número de patente.

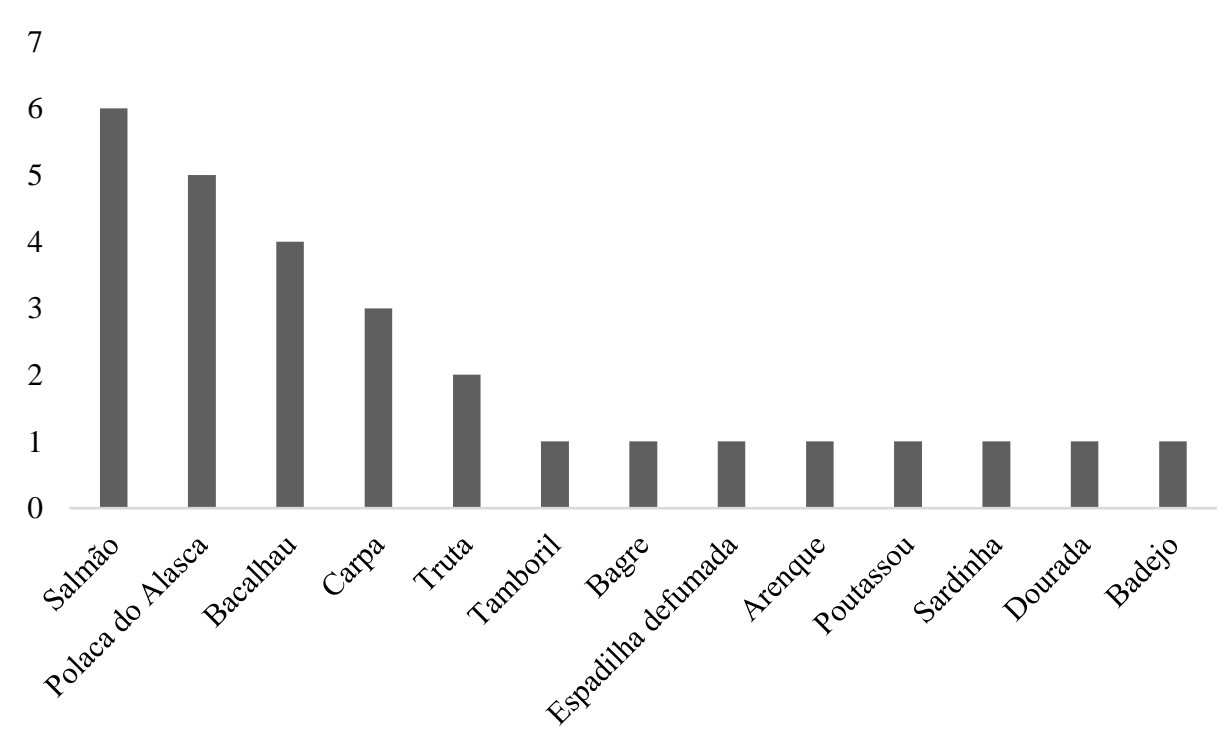

Fonte: Autoria própria (2021).

Até o ano de 2017, a Polaca do Alasca era considerada a espécie mais capturada de peixe, por ser uma excelente fonte de proteína, minerais e ácidos graxos ômega-3, além de apresentar valores de mercado mais acessíveis para os consumidores, o que pode estar associado com a sua maior utilização para a elaboração de produtos (Castro et al., 2019; Pauli-Yamada et al., 2019).

As espécies de peixes como tamboril, espadilha, arenque, poutassou e badejo podem ter sido menos utilizadas na composição dos patês por ser espécies menos comercializadas no mercado, já o bagre, a sardinha e a dourada são mais utilizadas para a elaboração de produtos quando comparadas com as outras espécies. No entanto, de acordo com o Instituto Português do Mar e da Atmosfera - IPMA (2021), a sardinha sofreu uma redução do número de indivíduos devido à pesca predatória para comercialização. Segundo Mendonça et al. (2017), o bagre é classificado na categoria "em perigo" pela Portaria MMA no 445/2014, de modo que sua captura foi proibida, o que justifica sua baixa utilização para a elaboração de produtos. 
Dentre os alimentos caracterizados como funcionais para a elaboração dos patês descritos nos documentos de patentes, estão os nutracêuticos obtidos do extrato de cogumelo; os cereais, como arroz, cevada, aveia, trigo sarraceno e sorgo; as frutas como maçã, uva, ameixa e banana; vegetais; turmarina; carvão vegetal; enzimas dietéticas e fitoterápicos.

Ao realizarmos buscas por trabalhos científicos relacionados ao tema foi possível verificar diferentes tipos de ingredientes funcionais inseridos nas formulações de patês com variados tipos de carnes. Na Tabela 3 são apresentadas as formulações do patê, o alimento funcional inserido, bem como sua bioatividade ou funcionalidade.

Ao analisarmos os testes sensoriais realizados com os diversos tipos de patês (Tabela 3), verificou-se que cerca de $60 \%$ dos produtos foram bem aceitos entre os provadores, com índice de aceitabilidade (IA) superior a 70\%, como no caso do patê adicionado com farinha da casca de kiwi (Soquetta, 2015) e patê adicionado de kefir de leite (Grando et al., 2016). Já a incorporação de dátil (Silva, 2011) e Bifidobacterium lactis (Costa, 2012) nos patês não apresentaram diferenças sensoriais que comprometessem a aceitabilidade dos produtos, enquanto a adição da fibra de trigo e óleo de linhaça (Giacomelli, 2014) contribuíram para o aumento do índice de aceitabilidade do patê, agregando características benéficas para o produto. Também foram observados a incorporação de globina, plasma (Viana et al., 2003) e castanha (Almeida, 2019) no realce do sabor do produto, e extrato do bagaço de uva como antioxidante natural (Carpes et al., 2020). A adição da quitosana auxiliou no aumento da vida útil do patê, bem como manteve as características sensoriais e nutricionais do produto (Silva, 2010). Cruxen et al. (2021) ao elaborarem patês de peixes (Oligosarcus robustus e Loricariichythys anus) contendo os prebióticos frutooligossacarideos e o probiótico Lactobacillus acidophilus LAFTI L10 relataram um produto final rico em proteínas e ácidos graxos insaturados (w3 e w-9), contendo $10 \%$ de prebióticos, além da alta aceitabilidade sensorial do produto. 
Tabela 3. Ingredientes funcionais utilizados na elaboração de diversos tipos de patês.

\begin{tabular}{|c|c|c|c|c|c|c|c|}
\hline $\begin{array}{l}\text { Formulação } \\
\text { patê }\end{array}$ & $\begin{array}{l}\text { Manteiga, atum, cenoura } \\
\text { ralada, leite em pó, ovo, pão } \\
\text { de forma, água, queijo } \\
\text { parmesão ralado, sumo de } \\
\text { limão, ervas da provença, } \\
\text { sal e pimenta, e } \\
\text { Nannochloropsis salina. }\end{array}$ & $\begin{array}{l}\text { CMS da pescada bicuda, } \\
\text { água, inulina (chicória } \\
90 \% \text { ), fécula de mandioca, } \\
\text { proteína da soja, sal } \\
\text { refinado, alho, cebola e } \\
\text { pimenta-do-reino-branca, } \\
\text { eritorbato de sódio, } \\
\text { polifosfato e sal de cura. }\end{array}$ & $\begin{array}{l}\text { Papada, fígado, toucinho, } \\
\text { fécula de batata, sal, } \\
\text { caseínato, polifosfato, } \\
\text { nitrito de sódio, ovo, } \\
\text { pimenta branca, noz } \\
\text { moscada, louro, tomilho, } \\
\text { alho em pó, ascorbato de } \\
\text { sódio e dátil. }\end{array}$ & $\begin{array}{l}\text { Carne de frango, sal, água, } \\
\text { farinha de cenoura, fécula de } \\
\text { batata, corante Carmim, } \\
\text { manjerona, orégano, pimenta } \\
\text { malagueta e grãos de kefir de } \\
\text { leite. }\end{array}$ & $\begin{array}{l}\text { Filé "Sassami" de frango, } \\
\text { tomate, cebola, leite, óleo } \\
\text { de canola, óleo de milho, } \\
\text { sal, salsinha e bagaço de } \\
\text { uva. }\end{array}$ & $\begin{array}{l}\text { Carne bovina, fígado } \\
\text { bovino, toucinho, óleo de } \\
\text { linhaça, caldo de } \\
\text { cozimento, fibra de trigo, } \\
\text { condimento, sal, proteína } \\
\text { texturizada de soja, } \\
\text { polifosfato de sódio, } \\
\text { glutamato monossódico, } \\
\text { eritorbato de sódio, } \\
\text { corante carmim, alho, } \\
\text { cebola, salsa e nitrito de } \\
\text { sódio. }\end{array}$ & $\begin{array}{l}\text { Peito e sobrecoxa de } \\
\text { frango, toucinho, água, } \\
\text { proteína isolada de soja, } \\
\text { condimento para patê, } \\
\text { tripolifosfato, cura } \\
\text { NaNO2, fixador, sal e } \\
\text { Bifidobacterium lactis. }\end{array}$ \\
\hline $\begin{array}{l}\text { Ingredientes } \\
\text { funcionais }\end{array}$ & $\begin{array}{l}\text { Microalga } \\
\text { Nannochloropsis salina }\end{array}$ & Inulina & Dátil & Kefir de leite & Bagaço de uva & $\begin{array}{l}\text { Fibra de trigo e óleo de } \\
\text { linhaça }\end{array}$ & Bifidobacterium lactis \\
\hline $\begin{array}{ll}\text { Bioatividade } & \text { ou } \\
\text { funcionalidade } & \end{array}$ & Fonte de ácidos graxos. & $\begin{array}{lcr}\text { A inulina } & \text { atua } & \text { fibra } \\
\text { dietética } & \text { solúvel } & \text { e } \\
\text { apresenta } & \text { propriedades } \\
\text { prebióticas, bem como } \\
\text { efeitos positivos no valor } \\
\text { calórico. }\end{array}$ & $\begin{array}{l}\text { Atua como antioxidante, } \\
\text { fibra funcional e fonte de } \\
\text { vitaminas e minerais. }\end{array}$ & $\begin{array}{l}\text { Atua no equilíbrio bacteriano } \\
\text { intestinal, controle dos níveis } \\
\text { de colesterol, aumento da } \\
\text { absorção de minerais e reduz } \\
\text { a intolerância à lactose. }\end{array}$ & $\begin{array}{lr}\text { Apresenta } & \text { atividade } \\
\text { antioxidante, } & \text { anti- } \\
\text { inflamatória, } \\
\text { antimicrobiana } \\
\text { anticarcinogênica. }\end{array}$ & $\begin{array}{l}\text { A fibra de trigo atua na } \\
\text { redução da } \\
\text { colesterolemia, na } \\
\text { diminuição da glicemia, e } \\
\text { promove sensação de } \\
\text { saciedade. } \\
\text { O óleo de linhaça aumento } \\
\text { os teores de ácidos graxos } \\
\text { nos alimentos. }\end{array}$ & Possui ação dietética. \\
\hline Referências & $\begin{array}{l}\text { Raposo, Mendes-Pinto, \& } \\
\text { Morais (2001) }\end{array}$ & et al., (2020) & 2011) & $\begin{array}{l}\text { Grando; Beilke, \& Palezi } \\
\text { (2016) }\end{array}$ & ernardi (2020) & Giacomelli (2014) & \\
\hline
\end{tabular}

Fonte: Autores. 
Research, Society and Development, v. 11, n. 2, e40211225886, 2022

(CC BY 4.0) | ISSN 2525-3409 | DOI: http://dx.doi.org/10.33448/rsd-v11i2.25886

Tabela 3. Ingredientes funcionais utilizados na elaboração de diversos tipos de patês (continuação).

\begin{tabular}{|c|c|c|c|c|c|c|c|c|c|}
\hline $\begin{array}{l}\text { Formulação do } \\
\text { patê }\end{array}$ & $\begin{array}{l}\text { Globina bovina, } \\
\text { carne, sais de cura, } \\
\text { condimentos e } \\
\text { caseinato de sódio. }\end{array}$ & $\begin{array}{lr}\text { Carne de frango, } \\
\text { pele de frango, água } \\
\text { gelada, sal, } \\
\text { polifosfato de } \\
\text { sódio, eritorbato de } \\
\text { sódio, corante } \\
\text { carmim. }\end{array}$ & $\begin{array}{l}\text { Água, carne suína, } \\
\text { pernil, toucinho, } \\
\text { bacon, sal, } \\
\text { aguardente, ácido } \\
\text { cítrico, orégano, } \\
\text { pimenta, proteína } \\
\text { isolada de soja, } \\
\text { tripolifosfato, sal de } \\
\text { cura, fixador de cor, } \\
\text { farinha de casca de } \\
\text { kiwi e corante } \\
\text { carmim. }\end{array}$ & $\begin{array}{l}\text { Paleta suína, } \\
\text { toucinho, globina, } \\
\text { plasma, água, sal de } \\
\text { cura, fixador de cor, } \\
\text { sal, polifosfatos, } \\
\text { amido, mostarda, } \\
\text { açúcar, gengibre e } \\
\text { pimenta. }\end{array}$ & $\begin{array}{lr}\text { Carne } & \text { bovina, } \\
\text { nitrito, eritorbato, } \\
\text { pimenta, gengibre, } \\
\text { açúcar, mostarda, } \\
\text { sal, } \quad \text { amido } \\
\text { dexnitrizado, água e } \\
\text { quitosana. }\end{array}$ & $\begin{array}{l}\text { Carne caprina, } \\
\text { toucinho, } \\
\text { condimentos, soro } \\
\text { de leite e lactulose }\end{array}$ & $\begin{array}{l}\text { Carne de ovelha, } \\
\text { carne de cabra, } \\
\text { castanha. Mix para } \\
\text { patê, leite, água de } \\
\text { cozedura e azeite } \\
\text { de oliva cru. }\end{array}$ & $\begin{array}{l}\text { CMS de aparas, sal, } \\
\text { condimentos, } \\
\text { amido de milho, } \\
\text { óleo de girassol, } \\
\text { água extrato de } \\
\text { guariroba. }\end{array}$ & $\begin{array}{l}\text { Filé de peixe, água, } \\
\text { sais de cura, } \\
\text { condimentos, } \\
\text { polifosfato, } \\
\text { frutooliogossacarídeos } \\
\text { e óleo de girassol. }\end{array}$ \\
\hline $\begin{array}{l}\text { Ingredientes } \\
\text { funcionais }\end{array}$ & $\begin{array}{l}\text { Globina bovina e } \\
\text { caseinato de sódio. }\end{array}$ & $\begin{array}{l}\text { Extrato do bagaço } \\
\text { de uva }\end{array}$ & $\begin{array}{l}\text { Farinha de casca de } \\
\text { kiwi }\end{array}$ & Globina e plasma & Quitosana & Lactulose & Castanha & $\begin{array}{l}\text { Extrato } \\
\text { guabiroba }\end{array}$ & $\begin{array}{l}\text { Lactobacillus } \\
\text { acidophilus } \text { Lafti L10 } \\
\text { e } \\
\text { frutooligossacarídeos } \\
\text { de cana de açúcar }\end{array}$ \\
\hline $\begin{array}{l}\text { Bioatividade } \\
\text { funcionalidade }\end{array}$ & $\begin{array}{l}\text { Caseinato de sódio } \\
\text { e a globina atuam } \\
\text { como fonte de } \\
\text { aminoácidos } \\
\text { essenciais. }\end{array}$ & $\begin{array}{lr}\text { Atua } & \text { como } \\
\text { antioxidante } & \mathrm{e} \\
\text { suplemento } & \\
\text { alimentar. } & \end{array}$ & $\begin{array}{l}\text { Atua como fibra } \\
\text { alimentar. }\end{array}$ & $\begin{array}{l}\text { O plasma atua } \\
\text { como fonte de } \\
\text { proteínas solúveis. } \\
\text { A globina atua } \\
\text { como fonte de } \\
\text { aminoácidos } \\
\text { essenciais. }\end{array}$ & $\begin{array}{l}\text { Atua } \\
\text { antimicrobiano } \\
\text { antioxidante. }\end{array}$ & $\begin{array}{l}\text { Atua no equilíbrio } \\
\text { da microbiota } \\
\text { intestinal, na } \\
\text { redução de amônia } \\
\text { no sangue, aumenta } \\
\text { a absorção de } \\
\text { minerais e reduz os } \\
\text { níveis de colesterol } \\
\text { no sangue. }\end{array}$ & $\begin{array}{l}\text { Atua } \text { como } \\
\text { antioxidante. }\end{array}$ & $\begin{array}{l}\text { Atua } \\
\text { antioxidante. }\end{array}$ & $\begin{array}{l}\text { Atua como probióbito } \\
\text { e prebiótico. }\end{array}$ \\
\hline Referências & Silva et al. (2003) & Carpes et al. (2020) & Soquetta (2015) & Viana et al. (2003) & Silva (2010) & Gomes et al. (2017) & Almeida (2019) & Pires (2020) & Cruxen et al. (2021) \\
\hline
\end{tabular}

Fonte: Autores. 
Cerca de 13,3\% dos patês não obtiveram boa aceitação, uma vez que a adição dos ingredientes funcionais interferiu negativamente no sabor dos patês, como no caso do patê adicionado de bagaço de uva (Cechin \& Bernardi, 2020) e de extrato de guariroba (Pires, 2020). Para o bagaço de uva foi atribuída nota 1 para intenção de compra, demonstrando que os consumidores certamente não comprariam o produto, já o extrato de guariroba deixou o produto com sabor amargo. Dos artigos revisados, 26,7\% não apresentaram dados de análise sensorial, sendo descrito apenas o processo de produção dos patês.

\section{Conclusão}

O estudo de prospecção cientifica e tecnológica agrega contribuições importantes para a ciência, principalmente, para o desenvolvimento de novos produtos na área de alimentos. A partir dos documentos de patentes analisados conclui-se que o Brasil não detém nenhum depósito de patente nesse tema, demonstrando que o país necessita de maiores investimentos na pesquisa científica, apesar de serem observados a publicação de trabalhos científicos, podendo estes ser uma oportunidade para o desenvolvimento de inovação para o setor de alimentos provenientes do pescado.

Em um cenário nacional de alta produtividade de pescado no país, incentivar pesquisas e parcerias entre as Instituições Acadêmicas e Empresas se tornam fundamentais para a efetivação de novas formulações adicionadas de ingredientes bioativos que promovam tanto a conservação do produto quanto a saúde dos consumidores. Como trabalhos futuros, recomenda-se o estudo de patentes usando outros produtos derivados do pescado ou demais produtos cárneos de origem animal, como linguiças, almondegas ou hambúrgueres, uma vez que patê de peixe pode não ser um dos produtos mais comercializados no Brasil.

\section{Agradecimentos}

Os autores agradecem à Fundação de Amparo à Pesquisa do Estado da Bahia - FAPESB.

\section{Referências}

Almeida, S. K. (2019). Avaliação da qualidade físico-química e sensorial de patês de ovino e de caprino com castanha portuguesa. Dissertação de mestrado, Programa de Pós-graduação em Zootecnia, Universidade Tecnológica Federal do Paraná, Dois Vizinhos, Brasil. https://repositorio.utfpr.edu.br/jspui/bitstream/1/4118/2/DV_PPGZO_M_Almeida\%2c\%20Samanta\%20Kelli_2019.pdf

Araujo Neto, E. R., Morais, L. S., \& Cunha, A. F. S. (2020). Mapeamento Tecnológico: uma prospecção de patentes e trabalhos científicos relacionados à própolis verde. Cadernos de Prospecção, 13(1), 268. https://doi.org/10.9771/cp.v13i1.32203

Batterink, M. H., Wubben, E. F. M., \& Omta, S. W. F. (2006). Factors related to innovative output in the Dutch agrifood industry. Journal on Chain and Network Science, 6(1), 31-45. https://doi.org/10.3920/JCNS2006.x063

Bernadino Filho, R., \& Xavier, L. C. A. (2019). Obtenção, rendimento e caracterização de CMS produzida com resíduos da filetagem de Tilápia do Nilo. Revista Brasileira de Agrotecnologia, 9(2), 01-04, doi.org/10.18378/rebagro.v9i2.7534

Brasil (2017). Ministério da Agricultura, Pecuária e Abastecimento. Decreto n 9.013, de 29 de março de 2017. Regulamento da Inspeção Industrial e Sanitária de Produtos de Origem Animal. Regulamenta a Lei $n^{\circ} 1.283$, de 18 de dezembro de 1950, e a Lei $n^{o} 7.889$, de 23 de novembro de 1989. RIISPOA. Brasília, DF, 29 de março de 2017. http://www3.servicos.ms.gov.br/iagro_ged/pdf/2511_GED.pdf

Carpes, S. T., Pereira, D., Moura, C., Reis, A. S., Silva, L. D., Oldoni, T. L. C., Almeida, J. F., \& Plata-Oviedo, M. V. S. (2020). Lyophilized and microencapsulated extracts of grape pomace from winemaking industry to prevent lipid oxidation in chicken pâté. Brazilian Journal of Food Technology, 23 , e2019112. https://doi.org/10.1590/1981-6723.11219

Castro, D. R. C., Campelo, D. A. V., Veras, G. C., Nunes, Z. M. P., Brabo, M. F., \& Rocha, R. M. (2019). Custo de produção e rentabilidade da produção de alevinos de tambaqui Colossoma macropomum no Nordeste paraense, Amazônia, Brasil. Custos e Agronegócio On-line, 15(ed. especial), 434-465. http://www.custoseagronegocioonline.com.br/especialv15/OK\%2016\%20alevinos.pdf

Cechin, K. S. R. S., \& Bernardi, D. M. (2020). Elaboração e análise sensorial de patê de frango com ômega-3 e antioxidantes naturais do bagaço de uva. FAG Journal of Health, 2(1), 93-102. doi:10.35984/fjh.v2i1.139

Costa, R. B. (2012). Estudo da viabilidade de microrganismo probiótico Bifidobacterium lactis em patê de frango com características simbióticas e sua ação na estabilização da oxidação lipídica. Dissertação de mestrado, Programa de Pós-graduação em Ciências e Tecnologia de Alimentos, Universidade Federal de Santa Maria, Santa Maria, Brasil. https://repositorio.ufsm.br/bitstream/handle/1/5733/COSTA\%2c\%20RENATA\%20BRUM.pdf?sequence=1\&isAllowed=y

Cruxen, C. E. dos S., Thiel, P. R., Souza, D. M., Costa, R. J., Filoda, O. F., Chaves, F. C., \& Fiorentini, A. M. (2021). Developing functional fish pâtés from Oligosarcus robustus and Loricariichythys anus with pre- and pro-biotic potentials. Food Bioscience, 44(1), 101449. https://doi.org/10.1016/j.fbio.2021.101449 
Cyrino, J. E. P., Galvão, J. A., Sonoda, D. Y., \& Frascá-Scorvo, C. M. D. (2019). Aquicultura, segurança alimentar e qualidade do pescado: esclarecendo mitos e insinuações. Aquaculture Brasil, (21a ed.). https://d335luupugsy2.cloudfront.net/cms/files/85938/1600201339Aquicultura_segurana_alimentar_e_qualid ade_do_pescado_esclarecendo_mitos_e_insinuaes.pdf

Das, M., Rajan, N., Biswas, P., \& Banerjee, R. (2022). A novel approach for resistant starch production from green banana flour using amylopullulanase. LWT - Food Science and Technology, 153(1), 112391. https://doi.org/10.1016/j.lwt.2021.112391.

Estanech, A., Oliveira, N., Amorim, E., Valadão, R., Torrezan, R., \& Oliveira, G. (2020). Efecto de la adición de almidón de mandioca, agua e inulina sobre las características tecnológicas del paté bicuda (Sphyraena tome, Fowler, 1903). Revista Chilena de Nutrición, 47(3), 359-365. dx.doi.org/10.4067/S071775182020000300359

FAO - Organização das Nações Unidas para Agricultura e Alimentação. (2016). El estado mundial de la pesca y la acuicultura 2016. Contribución a la seguridad alimentaria y la nutrición para todos. Roma. $224 \mathrm{pp}$.

FAO - Organização das Nações Unidas para Agricultura e Alimentação. (2018). Consumo de pescado na América Latina e no Caribe crescerá 33\% até 2030. https://www.fao.org/americas/noticias/ver/pt/c/1144412/\#: :text=At\%C3\%A9\%202030\%2C\%20espera\%2Dse\%20que,e\%20\%C3\%81sia\%20(\%2B20\%25).

FAO - Organização das Nações Unidas para Agricultura e Alimentação. (2020). El estado mundial de la pesca y la acuicultura 2020. La sostenibilidad en acción. Roma. https://doi.org/10.4060/ca9229es.

Flores, I. F. V. (2019). Desenvolvimento de novos produtos à base de pescado: paté de bacalhau e paté de ovas de pescado. Relatório de estágio de mestrado, Programa de Pós-graduação em Engenharia de Alimentos, Escola Superior de Biotecnologia, Universidade Católica Portuguesa, Porto, Portugal. https://repositorio.ucp.pt/bitstream/10400.14/30638/1/In\%c3\%aas\%20Flores\%20_\%20Mestrado\%20em\%20Engenharia\%20Alimentar.pdf

Freitas, M. C. J., \& Tavares, D. Q. (2005). Caracterização do grânulo de amido de bananas (Musa AAA-nanicão e Musa AAB-terra). Ciência e Tecnologia de Alimentos, 25(2), 217-222. doi.org/10.1590/S0101-20612005000200005

Gamito, A. C. R. (2019). Caracterização geral da linha de produção e controlo de qualidade de Bacalhau do Atlântico (Gadus morhua, Linnaeus, 1758) em ponto de sal. Dissertação de mestrado, Programa de Pós-graduação em Tecnologias de Produção e Transformação Agro-Industria, Faculdade de Ciências e Tecnologias, Universidade Nova de Lisboa, Lisboa, Portugal. Disponível em: https://run.unl.pt/bitstream/10362/94873/1/Gamito_2019.pdf

Giacomelli, C. (2014). Desenvolvimento de patê de fígado de bovino com distintas fontes de lipídios e inclusão ou não de fibra de trigo. Dissertação de mestrado, Programa de Pós-graduação em Ciências e Tecnologia dos Alimentos, Universidade Federal de Santa Maria, Santa Maria, Brasil. https://repositorio.ufsm.br/bitstream/handle/1/5759/GIACOMELLI\%2c\%20CARINE.pdf?sequence=1\&isAllowed=y

Gomes, D. R. S., Alves, M. G. H., Leite, S. C., Alves, J. E. A., \& Oliveira, C. A. (2017). Avaliação da cor objetiva de patê de carne de caprino adulto adicionado de soro de leite e lactulose. In Anais $69^{\circ}$ Reunião Anual da SBPC. (p. 1). UFMG.

Granato, D., Barba, F. J., Kovacevic, D. B., Lorenzo, J. M., Cruz, A. G., \& Putnik P. (2020). Functional foods: Product development, technological trends, efficacy testing, and safety. Annual Review of Food Science and Technology, 11, 93-118. https://doi.org/10.1146/annurev-food-032519- 051708

Grando, C., Beilke, L. \& Palezi, S. C. (2016). Elaboração de um patê de frango adicionado de microrganismo probiótico do gênero kefir e enriquecido com farinha de cenoura. Unoesc \& Ciência - ACET, 7(1), 61-68. https://portalperiodicos.unoesc.edu.br/acet/article/view/9874/pdf

IPMA - Instituto Português do Mar e da Atmosfera. (2021). Estação Piloto de Piscicultura de Olhão. https://www.ipma.pt/pt/pescas/eppo/sardinha/index.jsp

Irastorza, A., Zarandona, I., Andonegi, M., Guerrero, P., \& Caba, K. (2021). The versatility of collagen and chitosan: From food to biomedical applications. Food Hydrocolloids, 116(3), 106633. https://doi.org/10.1016/j.foodhyd.2021.106633.

Jaziri, A. A., Shapawi, R., Mokhtar, R. A. M., Noordin, W. N., \& Huda, N. (2021). Tropical marine fish surimi by-products: utilisation and potential as functional food application. Food Reviews International, 37(8), 1-26. doi: 10.1080/87559129.2021.2012794

Kolodziejski, W., Pawlikowski, B., Bykowski, P. J., \& Kolodziej, K. (2001). Alimentary product made of fish and vegetables in the form of paste or pie, exhibiting features of functional food and method of obtaining same. Depositante: MORSKI INST RYBACKI. PL198286B1. https://worldwide.espacenet.com/patent/search/family/020078400/publication/PL198286B1?q=p\%C3\%A2t\%C3\%A9\%20AND\%20fish\%20AND\%20A23L17 $\% 2 \mathrm{~F} 00$

Lobine, D., Rengasamy, R. R., \& Mahomoodally, M. F. (2021). Functional foods and bioactive ingredients harnessed from the ocean: current status and future perspectives. Critical Reviews in Food Science and Nutrition. https://doi.org/10.1080/10408398.2021.1893643

Maciel, E. S., Savay-Da-Silva, L. K., Galvão, J. A., \& Oetterer, M. (2015). Atributos de qualidade do pescado relacionados ao consumo na cidade de Corumbá, MS. Boletim do Instituto de Pesca, 41(1), 199-206. https://www.pesca.sp.gov.br/boletim/index.php/bip/article/view/41_1_199-206

Mendonça, J. T., Quito, L., Jankowsky, M., Balanin, S., \& Garrone Neto, D. (2017). Diagnóstico da pesca do bagre-branco (Genidens barbus e G. planifrons) no litoral sudeste-sul do brasil: subsídios para o ordenamento. (Relatório Técnico $\mathrm{n}^{\circ} 56$ ). São Paulo: Instituto de Pesca. https://www.pesca.agricultura.sp.gov.br/RT-56\%20final_2018.pdf

Micaelo, L. F., \& Castro, B. S. de. (2021). O Licenciamento de Patentes nas Instituições Científicas, Tecnológicas e de Inovação do Estado do Rio de Janeiro. Cadernos De Prospecção, 14(4), 1050-1066. https://doi.org/10.9771/cp.v14i4.42881

Moraes, M. S., Oliveira, L. P. S., Furtado, C. C., \& Gonzalez, F. G. (2017). Efeitos funcionais dos probióticos com ênfase na atuação do kefir no tratamento da disbiose intestinal. Revista UNILUS Ensino e Pesquisa, 14(37), 144-156. http://revista.unilus.edu.br/index.php/ruep/article/view/939/u2017v14n37e939

Mortier, K., \& Mortier, J. (2003). The application of a garnish to pate pasteurised or sterilised in sealed packaging. Depositante: OBEM BVBA. GB2398222A. Depósito: $06 \quad$ jan. 2003. https://worldwide.espacenet.com/patent/search/family/031501424/publication/GB2398222A?q=p\%C3\%A2 t\%C3\%A9\%20AND\%20fish\%20AND\%20A23L17\%2F00 
Moura, A. M. M., Gabriel Junior, R. F., Magnus, A. P. M., Bochi, F. S., \& Scartassini, V. B. (2019). Panorama das patentes depositadas no Brasil: uma análise a partir dos maiores depositantes de patentes na base Derwent Innovations Index. Brazilian Journal of Information Studies: Research Trends, 13(2), 59-68. doi: doi.org/10.36311/1981-1640.2019.v13n2.06.p59.

Mueller, S. P. M., \& Perucchi, V. (2014). Universidades e a produção de patentes: tópicos de interesse para o estudioso da informação tecnológica. Perspectivas em Ciência da Informação, 19(2), 15-36, doi: dx.doi.org/10.1590/1981-5344/1828

OMPI - $\quad$ Organização Mundial de Propriedade $\quad$ Intelectual. (2018). Comunicado de https://www.wipo.int/export/sites/www/pressroom/pt/documents/pr_2018_826.pdf

Paranhos, C. A. R., \& Sá, A. S. C. (2013). Políticas de inovação na Federação da Rússia. In Ministério das Relações Exteriores. Mundo Afora. (pp. 460-468). https://ses.sp.bvs.br/wp-content/uploads/2016/07/Mundo_Afora_10_incentivo-\%C3\%A0-inova\%C3\%A7\%C3\%A3o.pdf

Pauli-Yamada, L. F., Aquino, C. I., Marciano, M. A. M., Silva, A. M., \& Nogueira, M. D. (2019). Detecção de parasitos em filés de polaca do Alasca (Gadus chalcogrammus, Pallas, 1814) comercializados em São Paulo, Brasil. Revista Vigilância Sanitária em Debate, 7(3), 46-52. doi: doi.org/10.22239/2317269x.01304

PEIXE BR - Associação Brasileira de Piscicultura (2021). Anuário Peixe BR da piscicultura. Peixe BR.

Pires, C. L. S. (2020). Aplicação de extratos da casca de guabiroba (Campomanesia xanthocarpa) como agente antioxidante em patês de tilápia. Dissertação de mestrado, Programa de Pós-Graduação em Ciência e Tecnologia de Alimentos, Universidade Federal da Fronteira Sul, Laranjeiras do Sul, Brasil. https://rd.uffs.edu.br/bitstream/prefix/4256/1/PIRES.pdf

Rambe, P.; Khaola, P. (2021) The impact of innovation on agribusiness competitiveness: the mediating role of technology transfer and productivity, European Journal of Innovation Management, 1(1), 1-33. 10.1108/EJIM-05-2020-0180

Raniere, L. M., \& Delani, T. C. O. (2014). Banana verde (Musa spp): obtenção da biomassa e ações fisiológicas do amido resistente. Revista UNINGÁ Review, 20(3), 43-49. http://revista.uninga.br/index.php/uningareviews/article/view/1602

Raposo, M. F. J, Mendes-Pinto, M. M. \& Morais, R. M. (2001). Desenvolvimento de novos alimentos funcionais contendo microalgas. Trabalho apresentado no In V Encontro de Química de Alimentos.. http://hdl.handle.net/10400.14/6292

Santos, C. C. A., Queiroz, L. M., Perelo, L. W., \& Andrade, E. S. (2018). Prospecção tecnológica de patentes sobre cultivos de microalgas visando a produção de biodiesel. Cadernos de Prospecção, 11(4), 1057-1068. doi.org/10.9771/cp.v11i4.27206

Shirade, T. (2003). Process for sterilization and production of fish meat paste product with use of microbubble and sterile fish meat paste product obtained by the process. Depositantes: SEIZOU SHIRADE; TETSUYA SHIRADE. WO2005036992A1. Depósito: 17 out. 2003. https://worldwide.espacenet.com/patent/search/family/034463242/publication/WO2005036992A1?q=pn\%3DWO2005036992A1

Silva, D. J. (2010). Avaliação da qualidade de patê de carne adicionado de quitosana fúngica. Trabalho de Conclusão de Curso de graduação, Universidade Federal de Pernambuco, Recife, Brasil. https://repositorio.ufpe.br/bitstream/123456789/18236/2/SILVA\%2c\%20D\%c3\%a9bora\%20Joice\%20da.pdf

Silva, I. F. A. (2011). Estudo preliminar da adição de dátil na elaboração de um produto cárnico, paté de fígado de porco, de forma a obter um produto funcional. Dissertação de mestrado, Escola Superior de Biotecnologia, Universidade Católica Portuguesa, Portugal. https://repositorio.ucp.pt/bitstream/10400.14/10308/1/Tese_In\%c3\%aas\%20Fortuna_9-2012.pdf

Silva, J. G., Morais, H. A., Junqueira, R. G., Oliveira, A. L., \& Silvestre, M. P. C. (2003). Avaliação da estabilidade e da qualidade do patê de presunto, adicionado de globina bovina e de caseinato de sódio, como agente emulsionante. Ciência e Tecnologia de Alimentos, 23(1), 10-15. doi: doi.org/10.1590/S010120612003000100004

Sokolova, V. M., Talabaeva, S. V., \& Podkorytova, A. V. (2003). Method for producing of dietary paste-like canned fish foods. RU2250049C2. Depósito: 26 mar. 2003. https://worldwide.espacenet.com/patent/search/family/035635013/publication/RU2250049C2?q=p\%C3\%A2t\%C3\%A9\%20AND $\% 20$ fish\%20AND\%20A23L17\%2F00

Son, Y. S. (2003a). Functional boiled fish paste. Depositante: Young Suk Son. KR20040063700A. Depósito: 08 jan. 2003. https://worldwide.espacenet.com/patent/search/family/037354584/publication/KR20040063700A?q=p\%C3\%A2t\%C3\%A9\%20AND\%20fish\%20AND\%20A $23 \mathrm{~L} 17 \% 2 \mathrm{~F} 00$

Son, Y. S. (2003b). Functional processed fish products. Depositante: Young Suk Son. KR20040063707A. Depósito: 08 jan. 2003. https://worldwide.espacenet.com/patent/search/family/037354591/publication/KR20040063707A?q=pn\%3DKR20040063707A

Son, Y. S. (2003c). Functional boiled fish paste containing diet enzyme, herb medicines and functional materials. Depositante: Young Suk Son. KR20040064539A. https://worldwide.espacenet.com/patent/search/family/037355082/publication/KR20040064539A?q=pn\%3DKR20040064539A

Soquetta, M. B. (2015). Caracterização físico-química, microbiológica e compostos bioativos de farinhas de casca de bagaço de kiwi (Actinidia deliciosa) e aplicação em patê. Dissertação de mestrado, Programa de Pós-Graduação em Ciência e Tecnologia dos Alimentos, Universidade Federal de Santa Maria, Santa Maria, Santa Maria, Brasil. https://repositorio.ufsm.br/bitstream/handle/1/5788/SOQUETTA\%2c\%20MARCELA\%20BROMBE RGER.pdf?sequence=1\&isAllowed=y

Sozo, J. S., Motikawa, S., Martins, E., \& Alves, T. P. (2017). Análise sensorial e intenção de compra de pratos prontos à base de subprodutos de filé de salmão. Revista Brasileira de Engenharia de Pesca, 10(2), 113-129.

Viana, F. R., Silva, V. D. M., Bizzotto, C. S., Laboissière, L. H. E. S., Drumond, M. F. B., Oliveira, A. L., \& Silvestre, M. P. C. (2003). Globina e plasma bovinos, como substitutos de gordura em patê de presunto: efeito da incorporação sobre a composição química, textura e características sensoriais. Alimentos $e$ Nutrição, 14(1), 77-85. http://serv-bib.fcfar.unesp.br/seer/index.php/alimentos/article/view/841/721

Zolotokopova S.V, Zaporozhskaya S.P, Kosenko O.V., \& Lebedeva E.Y. (2021). Innovative Technology of fish-vegetable pate formulation with antioxidant and antiviral properties. Vestnik of Astrakhan State Technical University, Series: Fishing industry, 1, 114-124. https://doi.org/10.24143/2073-5529-2021-1-114124 